\title{
Collaboration as the Norm in Reference Work
}

The stereotype of the reference transaction is more or less unchanged since Samuel Swett Green's day, as involving precisely one librarian and one user. There are many common situations in which the reference transaction is not a one-to-one interaction, and this article will explore those situations. Additionally, this article argues that as network technology is increasingly utilized in reference work, situations in which the reference transaction is not a one-to-one interaction are becoming more common. Indeed, this article argues that as network technology is increasingly utilized in reference work, reference work will become fundamentally $a$ collaborative effort, to the benefit of both individual reference services and reference work in general.

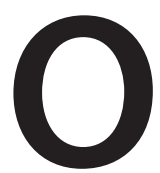

ur conception of the stereotypical reference transaction comes to us more or less unchanged since Samuel Swett Green's day. Green discusses what he refers to as "personal relations between librarians and readers," suggesting that the value of the library to the user is heavily influenced by the quality of the interaction between the user and the librarian. ${ }^{1} \mathrm{He}$ provides several examples of the sort of personalized assistance that he suggests a librarian should offer to a user.
All of the examples that Green provides, however, involve precisely one librarian and one user.

Another seminal author on the topic of library reference, Taylor, adopts Green's implicit model of the reference transaction being a one-to-one interaction. ${ }^{2}$ Taylor's concern was not to make a case for interaction between librarian and user, as Green's was; rather, Taylor's concern was to elucidate the steps that librarians must lead the user through during this interaction. As with Green, however, Taylor implicitly assumes that there is one and only one librarian and user in this interaction.

The major textbooks on reference work similarly treat the reference transaction as a one-to-one interaction. ${ }^{3}$ On the one hand, it is perfectly reasonable that textbooks would take this approach, since one-to-one interaction is the simplest model of interpersonal communication and is how many models of dialogic communication portray that communication. ${ }^{4}$ On the other hand, like many models, the model of the reference transaction as a oneto-one interaction is overly simplistic. There are many common situations in which the reference transaction is not a one-to-one interaction, and this article will explore those situations. Additionally, as network technology is

\section{Jeffrey Pomerantz}

Jeffrey Pomerantz is Associate Professor, School of Information and Library Science, University of North Carolina at Chapel Hill. Submitted for review July 19, 2004; revised and accepted for publication April 19, 2005.

Reference \& User Services Quarterly, vol. 46 , no. 1 , pp. $45-55$

(c) 2006 American Library Association. All rights reserved.

Permission granted to reproduce for nonprofit, educational use. 


\section{FEATURE}

increasingly utilized in reference work, situations in which the reference transaction is not a one-to-one interaction are becoming more common. Indeed, this article argues that as network technology is increasingly utilized in reference work, reference work will become fundamentally a collaborative effort.

\section{REFERENCE WORK HAS ALWAYS BEEN COLLABORATIVE}

Tyckoson discusses the two historically predominant models of reference service: the model in which the librarian provides an answer to the user's question, and the model in which the librarian teaches the user to use the library and to answer her own questions. ${ }^{5}$ Regardless of which model a library or a librarian practices, however, it is necessary for the librarian and the user to collaborate.

The reference transaction is a collaborative effort between the librarian and the user, in the sense that all interpersonal communication is a collaborative effort between the participants in a communication process. The field of communication studies known as discourse analysis is based on what Clark and Wilkes-Gibbs refer to as the "conversational model" of communication. ${ }^{6}$ According to this model, both individuals involved in a conversation are active participants in constructing meaning in the context of the conversation. Clark and Schaefer build on this idea of mutual construction of meaning, and propose what they refer to as a contribution. A contribution is a combination of a speech act-that is, the utterance of some meaningful content-and the acceptance of that content. This acceptance occurs when "the speaker and addressees mutually believe that the addressees have understood what the speaker meant." (This situation is summed up most artfully by the character of Prince Geoffrey in the 1968 film The Lion in Winter, when he states that: "I know. You know I know. I know you know I know. We know Henry knows, and Henry knows we know it.") When that mutual acceptance of the speaker's meaning is accomplished, the original speech act achieves the status of "common ground" between the speaker and the addressee, for the purposes of the conversation.

The reference transaction is not, however, an ordinary conversation. The conversation that is the reference transaction is complicated by the fact that the participants are not simply exchanging statements; rather, one of the participants is asking a question of the other. Further, the questioner may be asking a question on a topic about which he may know little or nothing. Belkin, Oddy, and Brooks refer to this as an "anomalous state of knowledge," and claim that "in general, the user is unable to specify precisely what is needed to resolve that anomaly." What sets the reference transaction apart from an ordinary conversation is that the participants attempt to achieve common ground on a topic about which neither may possess any knowledge. In a way, it is amazing that common ground is ever achieved in reference transactions; it is for this reason that Lynch refers to the reference transaction as a process of "mind-read-

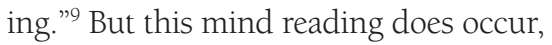
and it is through the process of mutual construction of meaning that it is able to occur. It is because the reference transaction is a conversation, and conversations are collaborative efforts between the participants, that the reference transaction is able to succeed in resolving the user's anomalous state of knowledge, or in providing the user with the knowledge to resolve it herself.

While the conversation that is the reference transaction is a collaborative effort between the librarian and the user, there may also be a conversation that leads up to the reference transaction. This is the case when the user in the reference transaction is acting as an agent for another. Gross refers to a reference question of this type as an "imposed query," which is a reference question that is "set in motion when a person gives a question to someone else to resolve." 10 As Gross points out, much of reference work is predicated on the assumption that through conversation, the librarian can elicit informa- tion about the user's situation and the context of the question, and thereby arrive at an understanding of the question. This situation and context is, however, not present for a user who is acting as an agent. On the other hand, in order for the agent to be in possession of the question in the first place, and for the principal to be comfortable with the agent representing her to a reference service, the principal and the agent must presumably have a conversation in order for the former to convey to the latter her information need. Although this conversation is most likely hidden from the librarian (because it takes place prior to the reference transaction), it must take place in order for the principal and the agent to have arrived at common ground sufficient for the agent to operate.

Regardless of whether its purpose is question answering or instruction, the reference transaction is fundamentally a collaborative effort. Collaboration necessarily occurs between the librarian and the user, and may also occur between a principal and an agent. The remainder of this article, however, will focus on collaborations on the other side of the reference transaction: between librarians, and between reference services.

\section{COLLABORATION AT THE DESK}

Perhaps the most familiar form of collaboration between librarians in reference work is also one of the simplest: the referral. Childers draws a distinction between "steering," or providing directions for the user to another service, and "referring," or making contact with that other service for the user. ${ }^{11}$ In both cases, a librarian directs the user to another librarian or reference service, and collectively the librarians at these different services answer the user's question. In the case of Childers's steering, the librarians may never directly collaborate with one another about the user's question; they may never meet or even know that each other exists except in the most abstract way. Indeed, in such a case, the referring librarian may 
never even know if the user contacts the referred-to service. Thus, a steered referral is a collaborative effort, but only barely: it is collaborative in the sense that multiple librarians are part of a virtual team that works on answering a question, though that team is connected in that task only by the user. A referred referral, then, according to Childers, is one in which the librarians actually do directly collaborate with one another on the user's question.

Hawley takes a different approach to categorizing types of referrals, drawing a distinction between an "intra-library" referral, where the user is referred to another librarian within the same library, and an "extra-library" referral, where the user is referred to another library altogether. ${ }^{12}$ In an intra-library referral, it can probably be assumed that the referring and the referred-to librarians at least know each other, and it allows for the possibility that they will actively collaborate in answering the user's question. This is probably the simplest model of true collaboration in reference work, when the librarians are physically collocated, and collaborate in person. Reasons for this type of collaboration may vary: one librarian may have expertise that the other does not have, or one librarian may simply be stumped and two heads are better than one. This form of collaboration is a conversation in the sense discussed above, only instead of being between a librarian and a user, it is between two librarians.$^{13}$ The user is thus in the position of being the user of the artifacts of the conversation-that is, the common ground agreed upon by the librarians participating in the conversation. This common ground will hopefully include an answer to the user's questions. In an extra-library referral, on the other hand, the user may be either steered or referred: that is, the librarian may simply tell the user to go to another service (with contact information in hand, one hopes), or the librarian may make contact with that other service for the user.

The universe of possibilities for interaction between librarians in referrals is pretty much exhausted by the situa- tions described above: collaboration in person, a referral made to a colleague within the library, and a referral made to another library or service. In the case of a referral, the universe of possibilities is that the burden is on the librarian or on the user to contact that other service. It was only after the adoption of the telephone at the reference desk, however, that it was feasible for the librarian to contact the referred-to service. Most of the literature on providing reference service by telephone discusses the telephone as a tool for the provision of reference service. ${ }^{14}$ This literature treats the reference transaction as a collaborative effort between the librarian and the user, as discussed above. Very little of this literature mentions the telephone as a tool for contacting other librarians or reference services, though this is a very obvious use of the telephone. Indeed, Janes, in a 2003 Luminary Lecture at the Library of Congress (www.loc.gov/ rr/program/lectures/janes.html), stated that his mother, who was herself a reference librarian, always said that "her favorite reference tool was the telephone." ${ }^{15}$ It seems unlikely that Mrs. Janes is alone in this. Prior to the adoption of the telephone as a reference tool, however, extra-library referrals could only be steered-it would have been impossible for the librarian to make contact with another library or service without leaving the desk.

In this same lecture, Janes also mentions the example of an art question being submitted to the Internet Public Library (IPL). In this case, Janes states, the question might be forwarded to the Ask Joan of Art service, because a subject specialist in art would likely be able to provide a better answer than a subject generalist could. But, Janes points out, in this situation it would be up to the librarian to know that Ask Joan of Art is the best service to provide an answer to the user. A reference service is inevitably going to receive questions that it cannot answer, and for which the best alternative service for answering those questions is unclear. There are books that attempt to fill this niche by providing answers to unusual questions, such as The Book of Answers by the New York Public Library, and the many books by Feldman. ${ }^{16}$ Even armed with such books, however, it is still up to the librarian to know that an answer may be found in one of those books. And if an answer cannot be found in such a book, what is a librarian to do? Or, more to the point, what was a librarian to do in the days before Google?

\section{COLLABORATION FORUMS}

In the situation where a librarian does not know where to find an answer, and also does not know to where to refer the user, the best option may be to send out a message in a bottle, as it were. The column, titled The Exchange, which appeared in $R Q$ from 1965 through its entire run, and subsequently in Reference and User Services Quarterly (RUSQ) through 1999, fulfilled this function. The archives of The Exchange are now available online to members of the Reference and User Services Association (RUSA) (http://cs.ala .org/rusa/login/index.cfm). As a forum for the exchange of "tricky questions, notes on unusual information sources, and general comments concerning reference problems and their solutions," The Exchange allowed librarians to seek input from other librarians whom they may not even have known. ${ }^{17}$ The Exchange effectively allowed librarians to collaborate with the whole world (or at least the whole RQ- and RUSQreading world) on answering reference questions.

Approximately thirty years later, another venue for global collaboration, as it were, was launched: The Stumpers discussion list (domin.dom.edu/depts/ gslis/stumpers). Stumpers was founded in 1992 as a forum for librarians to post reference questions to which they are unable to find answers, and thereby to enlist the expertise of a distributed network of other Stumpers subscribers (who are mostly, if not entirely librarians) in locating answers. ${ }^{18}$ In this sense, Stumpers and The Exchange are identical in purpose. The only significant differences between these two forums are the media of collaborationelectronic and paper, respectively-and 


\section{FEATURE}

the speed with which questions may consequently be answered.

Both Stumpers and The Exchange are unique forums. Feeney mentions that prior to the founding of Stumpers, the LIBREF discussion list was occasionally a forum for the exchange of questions and answers between librarians (and sometimes still is), and such exchange is common on many library discussion lists dedicated to specific topics or services, or service to particular user groups. ${ }^{19}$ To this author's knowledge, however, no other discussion list but Stumpers has ever been entirely dedicated to this purpose. Similarly, there has never been another forum for question-and-answer exchange in the print library literature like The Exchange. Stumpers and The Exchange are the only existing structured forums (as opposed to the informality of personal and discussion-list conversations) for knowledge sharing between librarians, outside of the institutional framework of their respective libraries. To a certain extent, the existence of these forums is a demonstration of librarians' commitment to their users: librarians will seek out answers to difficult questions even on their own time. More importantly, however, these forums are communities of what Burbules refers to as "distributed credibility," in which the members of the community pool their knowledge and thereby replace "an individual judgment with a collective intelligence." ${ }^{20}$ These forums allow the reference transaction to extend beyond just one librarian-they allow reference work to be a community exercise.

\section{COLLABORATION ONLINE}

The Stumpers discussion list was founded at approximately the same time that another new form of reference service was coming into existence: the AskA service. AskA services are themselves outgrowths of a slightly older form of reference service utilizing networking technology: the digital reference service.

\section{Asynchronous Digital Reference}

The earliest digital reference services were developed in the mid-1980s. They were offered, via e-mail, as outgrowths of existing reference-desk services in academic and special libraries. ${ }^{21}$ These digital reference services were developed both to extend the hours of availability of the reference desk, and to experiment with the new technology of campus-wide networks. In the early- to mid-1990s, reference services began to appear on the Internet that were not affiliated with a library. ${ }^{22}$ Lankes refers to services of this type as "AskA" services, since services of this type allow users to ask questions of librarians or experts who specialize in a particular subject: for example, art (Ask Joan of Art), mathematics (Ask Dr. Math), or oceanography (Ask Shamu). ${ }^{23}$ These early digital reference services, both those affiliated with libraries and AskAs, were standalone services, in the sense that submitted reference questions were answered solely by the librarians and experts within the library or service.

As at the physical reference desk, collaboration occurs between librarians and experts in digital reference and AskA services. While these services are by nature distributed, services affiliated with a library are often staffed by the same librarians as staff the reference desk, and those unaffiliated with a library often have headquarters in a physical location. For example the Internet Public Library (www.ipl.org) is based in the School of Information at the University of Michigan at Ann Arbor, and many of IPL's volunteers are students in the school. When librarians and experts are physically collocated, they may collaborate in person. The distributed nature of these services also allows librarians and experts to collaborate via mediated channels, such as telephone, e-mail, and instant messaging (IM). When such channels are used for collaboration, however, it becomes less important that librarians and experts are physically collocated. It thus becomes as easy for librarians to collaborate with others outside of the service as within it.

In the mid-1990s, AskA Services began to form into consortia. The purpose of these consortia was to provide a vehicle for services to swap out-ofscope and overflow questions, so that if one service received a question that it could not or would not answer for some reason, it could be forwarded to another service in the consortium that could answer it. Digital reference services that are members of these question-swapping consortia therefore not only receive questions submitted directly by users, but also questions triaged from other services. Pomerantz, Nicholson, and Lankes define triage as "the assignment and routing of a question to a digital reference service, and to a reference or subject expert within a service." ${ }^{24}$

There are a number of such consortia, both national and local. The Metropolitan Cooperative Library System (MCLS, www.mcls.org) is an association of public, academic, and corporate libraries in the greater Los Angeles area, which as of this writing includes forty-four full and twenty-six associate members (www.mcls.org/webpublic/ libraries/libraries.cfm). As of this writing the Virtual Reference Desk (VRD) has thirty-two AskA service participants, which themselves span a range of sizes from one-person labors of love to large, institutionally sponsored operations, and which geographically span the United States. ${ }^{25}$ The QuestionPoint service and its affiliated software is used by one thousand libraries in twenty countries. ${ }^{26}$ These three services are merely examples to illustrate the range in size, geography, and types of participating organizations of such questionswapping consortia; there are many others both within the United States and worldwide.

\section{Synchronous Digital Reference}

Synchronous digital reference services have also formed consortia. A range of applications have been used to provide synchronous digital reference services, from IM applications such as AOL IM, 
to applications designed specifically for chat-based reference. This latter category includes several applications: Tutor.com's Virtual Reference Toolkit (www.vrtoolkit.net), the eponymous 24/7 Reference (www.247ref.org), the Library of Congress and OCLC's QuestionPoint (www.questionpoint.org), and Docutek's VRLplus (www.docutek. com), to name only the most widely used. For an excellent review of the features of these and other applications for chat-based reference, see Ronan. ${ }^{27}$

Several consortia of synchronousreference services have been formed since the late 1990s. Some of these consortia are composed of libraries using the same software application, such as QuestionPoint, Virtual Reference Toolkit, and 24/7 Reference. Some of these consortia are composed of libraries within a single state or geographic region, such as NCknows, a consortium of libraries in North Carolina (www .ncknows.org), QandA-NJ, a consortium of libraries in New Jersey (www.qandanj .org), the CLEVNET (Cleveland, Ohio) Library Consortium's KnowItNow24x7 (www.knowitnow24x7.net), and the Western New York Library Resources Council's Ask a WNY Librarian (www .wnylrc.org).

Joining a consortium of reference services obligates a library to support users from outside its primary user community, since even if all libraries answer questions from their own users first, there will inevitably be times when a library will answer questions from another library's users. In a study of the NCknows service, however, Pomerantz and McClure found that 75 percent of users of the NCknows service are from within the state of North Carolina, and that 86 percent of users of the chat-based reference service offered by the Public Library of Charlotte and Mecklenberg County, North Carolina (PLCMC, www.plcmc.org) are from within the state of North Carolina, and 67 percent are from users in the Charlotte area. ${ }^{28}$ (PLCMC is now part of the NCknows service, but their chat-based reference service predates NCknows by two years.) Thus, while joining a consortium obligates a library to support other library's users, this may be a com- paratively small percentage of the users supported.

The author and colleagues found, further, that NCknows librarians handled 45 percent, and the rest of the $24 / 7$ consortium of which NCknows is a member handled 55 percent of the users who logged into the NCknows service. Even more dramatic, PLCMC librarians handled 16 percent, and the 24/7 network handled 84 percent of the users who logged into PLCMC's (pre-NCknows) chat service. NCknows and the PLCMC made out well in this: for a comparatively minimal investment in supporting users outside of their primary user communities, these chat services increased several times over the volume of transactions that they were able to handle during their hours of service, in addition to dramatically expanding the number of hours that chatbased reference service could be offered to their primary user community.

\section{Network Effects}

The purpose of a library consortium is to share resources between libraries, to leverage scarce resources such as materials, time, or money. There are many arenas in which libraries form consortia: interlibrary loan, copy cataloging, software purchasing, and vendor negotiations, to name only a few. ${ }^{29}$ Reference work, however, is not one of the arenas in which libraries have traditionally formed consortia. Desk reference services have never joined forces in a consortia.

There is one resource that is as scarce as any of the others-perhaps more so-but intangible, and so not often thought of as a resource that may be shared in a consortium: knowledge. Knowledge is, however, precisely the resource that is shared in consortia of digital reference services. Although desk reference services have never formed consortia, consortia are common among digital reference services. While there are undoubtedly standalone digital reference services that collaborate with no others, there are many that are part of such question-swapping consortia. Furthermore, this trend towards collaboration between digital reference services seems to be increasing. Consider the dramatic growth in the number of members of various consortia over the past few years: From 2002 to 2004 VRD more than doubled its number of participants, from fifteen to thirty-two, while within that same timeframe the QuestionPoint service grew from "over 300 libraries" to one thousand. ${ }^{30}$

This increase in the size of questionswapping consortia is a classic case of network effects, whereby the value of a network increases as the number of users of that network increases. An example of this is the telephone network: one telephone alone is useless, but the value of each telephone increases as the number of telephones in the network increases and it becomes possible to call more people. This rule is referred to as Metcalfe's Law in reference to computer networks, and Reed's Law in reference to social networks. Reed suggests that the value of membership in a social network—such as a question-swapping consortium-"is the value of the set of optional transactions that are afforded by the system or network." ${ }^{\text {"1 }}$ Thus, the value of a question-swapping consortium is that the more other digital reference services are members, the more other services are available to which your service can potentially triage questions. Further, the more other services that specialize in particular subject areas are members of the consortium, the more questions your service can triage to appropriate other services to be answered by subject specialists.

Lavender, Nicholson, and Pomerantz, however, discuss the difficulty that question-swapping consortia have had in convincing museums and other subject-specialist services to join. ${ }^{32}$ This difficulty is caused in part by the fact that museums often do not have a reference department as libraries do, and in part because the questions that museums do receive are often so specific to material in the museum's collection that no other service would be able to successfully provide answers. Lavender, Nicholson, and Pomerantz suggest that in order to make participation in question-swapping consortia attractive to museums and other subject-specialist services, "modified publicity materials, 


\section{FEATURE}

question forms, and infrastructure will be needed." ${ }^{33}$ In other words, as question-swapping consortia become more formalized and develop standards for the various aspects of managing the service, they will have a greater appeal to a greater number of different types of digital reference services.

Early in the development of these question-swapping consortia, Lankes foresaw the need for standards for exchanging questions between services. ${ }^{34}$ In a white paper, Lankes proposed what he called the Question Interchange Profile (QuIP), a set of metadata elements for passing information about a question between digital reference services. QuIP has evolved considerably since 1999, and is currently in the process of being formalized as a standard by the National Information Standards Organization (NISO) and the Library of Congress, under the name of the Question/Answer Transaction Protocol (QATP) (www.loc.gov/standards/ netref). The purpose of QATP is to provide a set of metadata elements that may provide a "wrapper" for a question or a question-and-answer pair, containing all of the information that a digital reference service may need when receiving a question from another service. QATP is only the first and, at this point in time, the most developed standard for managing question-swapping consortia; it is likely that other standards will follow. Indeed, Maxwell suggests that only once standards are developed will digital reference take "the next major step in its development," and that this next major step will include new methods for sharing knowledge. ${ }^{35}$

\section{Asynchronous Digital Reference Redux}

From highly standardized services, this discussion now turns to one of the least-standardized services on the Web these days: blogs. Doctorow and others offer this definition of blogs:

A blog is a web page that contains brief, discrete hunks of information called posts. These posts are arranged in a reverse-chronologi- cal order (the most recent posts come first). Each post is uniquely identified by an anchor tag, and it is marked with a permanent link that can be referred to by others who wish to link to it. ${ }^{36}$

In some ways blogs are journals, but blogs require us to reinvestigate our understanding of the term. Some might post their private thoughts on their blog (a more traditional understanding of a journal), while others might use their blog to create journals of news events, political happenings, or technological developments. Indeed, blogs of all of these types and more exist.

Blogs have the potential to take on the role that The Exchange and Stumpers have previously filled in the library world: forums for knowledge sharing between reference librarians, rather than between reference services. While blogs have not yet been utilized for this purpose, they have a great deal of potential for collaborative-reference work. Blogs have to date been used by libraries primarily as high-tech bulletin boards, as venues for publishing newsletters and press releases, or making announcements about library services. ${ }^{37}$ Some have suggested using blogs as venues for making available compiled resources, and there are many blogs maintained by librarians that are venues in which the blogger discusses news and events that they consider important to the library community. ${ }^{38}$ Blogs may, however, be fruitfully used by libraries for more interactive purposes, specifically for reference work where more than one librarian may contribute to an answer.

While there are to date no blogs that the author is aware of that are being used for library reference work, there is one blog that has created a forum for users to post questions and answers: Ask MetaFilter (ask.metafilter.com). MetaFilter's documentation states that the site "exists to break down the barriers between people, to extend a weblog beyond just one person, and to foster discussion among its members" (www .metafilter.com/about.mefi). This is the premise behind the suggestion that blogs may be used for library reference: to break down the barriers between librarians, to extend a reference transaction beyond just one librarian, and to foster discussion among librarians-in short, to allow reference work to be a community exercise. Burbules's notion of distributed credibility suggests that a community of librarians may contribute a fuller and more complete answer than any one single librarian might be able to do. ${ }^{39}$

Ask MetaFilter has the drawback, however, that any registered user may contribute an answer to a question, and anyone may register-so that there is no control over the accuracy or completeness of the answers provided. At the time of this writing, for example, there is a posting on Ask MetaFilter that asks, "Can someone please explain to me the difference between owning and/or licensing proprietary software, or if there is even a difference in those two terms?" This posting received five responses in the approximately twentyfour hours since it was posted, and not a single one was from a copyright lawyer, or even a lawyer of any stripe, and none discussed current copyright or intellectual property laws. For a blog to be useful for library reference work, standards must be implemented to regulate who has the authority to answer questions, and possibly also who has permission to ask questions. Such standards already exist in desk- and digital reference services, however, so implementing them for blog reference would simply be a new application of the same. As with question-swapping consortia, in order for blogs to appeal to digital reference services, they must become more formalized and standards must be developed.

\section{DISCUSSION}

The examples discussed of synchronous and asynchronous forms of reference work illustrate that there are several possibilities for collaboration in reference work:

- between users, or perhaps more accurately, between potential users (for example, the imposed query); 
- between the librarian and the user (for example, the traditional reference transaction);

- between librarians, both within a library (for example, colleagues collaborating on answering a question) and across libraries (for example, Stumpers); and

- between services (for example, question-swapping consortia).

Figure 1 represents these possible collaborations, the boxes indicating the participants and the arrows indicating the collaborations between participants.

Prior to the adoption of the telephone as a reference tool, when all reference services were standalone services, a reference service could arguably get away with referring a user to another service and then putting the burden on the user to contact the referred-to service. These days, however, many information services are available to users online: digital reference services, help desks in organizations of all types, even search engines. As Lavender, Nicholson, and Pomerantz state, "the typical user is not concerned with a specific collection within a specific library, but rather with his information need and consequently with getting an answer to their question from any collection." ${ }^{40}$ While they were referring to users of reference services in library special collections, the same is often true of users of reference services in general: the user is concerned with finding an answer to his question, and may not be particularly concerned with where that answer comes from. Indeed, the user may not even be particularly concerned with the authority and completeness of that answer, which may explain the extensive use that Web search engines are currently receiving, while digital reference services are receiving far less use. ${ }^{41}$

Durrance suggests that a measure of the quality of the reference service provided is the user's willingness to return to ask another question of the same librarian..$^{42}$ In a digital reference service, however, the user may have no control over which specific librarian he asks a question of; an alternative to Durrance's criterion for a digital reference service is therefore the user's willingness to submit another question to the same service. By virtue of being online, all digital reference services are more or less equally accessible; just because a chat reference service is affiliated with a user's local library does not mean that that service is the one to which that user will choose to submit a question. Therefore, just as a librarian has one chance to impress a user before that user makes a judgment about her willingness to return to that librarian, so too does a digital reference service have one chance to impress a user before that user makes a judgment about her willingness to return to that service. And, given the ease with which a user may locate other digital reference services, if a user is unwilling to return to a service, it is possible that the service has lost that user for good. ${ }^{43}$ DeSouza refers to this phenomenon in the commercial sector as "customer defection": service defectors are "customers who leave because of poor service," while product defectors are "customers who switch to a competitor that offers a superior product." ${ }^{\prime 4}$ These two forms of defection presumably often go hand-inhand, the former leading to the latter. DeSouza claims that it may be impossible to get a product defector back as a customer, and it is likely so with digital reference users as well. Once a user is unwilling to return to a service, and has found another service or services with which he is satisfied, it may be impossible to get that user back.

Given the ease and convenience with which users may find information online (poor in quality though it may be at times), and the fact that users are concerned with finding answers to their questions regardless of the source, reference services can no longer simply provide referrals, can no longer simply steer users to other services. Instead, when making referrals, reference services must act as the user's agent to make contact with other reference services. Indeed, this is no more than adhering to RUSA's Guidelines for Information Services, which states that "Before referring a user to an agency, expert, or other library, information-services personnel should confirm that the agency, expert, or library to which the user is being referred can provide the information and will extend its services to that user." ${ }^{\prime 5}$

The fact that users are concerned with finding answers regardless of the source also puts pressure on reference services to provide answers instead of teaching the user to answer her own questions. With regard to the issue of question answering or instruction, technology is a double-edged sword for reference services: to a certain extent it is users' use of technology that enables them to be so demanding of answers, but use of technology also makes it more difficult to conduct the reference transaction that allows the librarian to collaborate with the user to resolve her information need. ${ }^{46}$ In a study of a chatbased reference service, however, Hull found that some form of instruction occurred in the majority of chat sessions, and frequently unintentionally-that is, instruction was incorporated into the flow of the reference transaction. ${ }^{47}$ Time will tell which of the models of reference service discussed will prove to be most appropriate for onlinereference services, or if new models will emerge. In any case, when reference

Figure 1: Possible collaborations in reference work

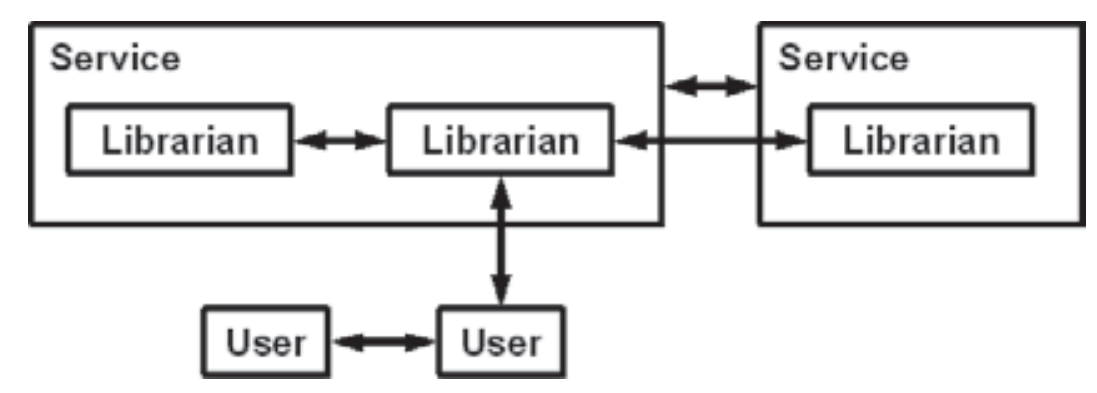

volume 46, issue 1 | 51 


\section{FEATURE}

services are under pressure to provide answers to users, collaboration between services is critical. A digital reference service that can insure that its users receive answers-even if this means referring the question to another service that will provide those answers-has a better chance of attracting repeat users. In order to survive individually, it is incumbent on digital reference services to collaborate.

In a sense, this is an argument for digital reference services to be black boxes to the user. If users are concerned more with getting their questions answered than with the specific library or other source that provides those answers, then they are unlikely to be particularly interested in the mechanics of how a digital reference service manages to provide their answer. If those mechanics involve forwarding a question to another service to be answered, then so be it. Many users may not understand how Google operates, and are satisfied simply that it does what it does well; so, too, many users are likely to care only that they receive useful and high-quality information quickly from a digital reference service.

The argument for digital reference services being a black box to the user works, however, only up to a point. One of VRD's Facets of Quality is privacy of the communication between the user and the librarian. ${ }^{48}$ To maintain privacy, VRD recommends that digital reference services "receive consent from users before sharing transaction data or identifying information with a third party" - and another digital reference service is just such a third party. Janes lists the most common information asked for by digital reference services on question-submission webforms and "consent to share transaction data" is not one of them, though it would not be difficult to add this to a webform ${ }^{49}$

Maintaining users' privacy, however, requires more than simply asking for users' consent to share transaction data. VRD recommends further that digital reference services "remove all identifying information from the question-answer sets before posting in a public archive." Whether or not a service's archive of transactions is public, however, it is important that users' privacy and confidentiality is maintained, consistent with ALA's Code of Ethics. ${ }^{50}$ On the other hand, there is a legitimate need for libraries to maintain data about users and users' questions in order to perform evaluation of the service. These two needs-privacy and evaluation-appear at first glance to be incommensurate, especially in the current political climate where users' privacy is threatened by legislation such as the USA PATRIOT Act, and librarians are responding by destroying library records. ${ }^{51}$ There are, however, ways of removing personally identifying data from transactions short of wholesale deletion. Nicholson and Smith outline perhaps the best-developed method for cleaning digital reference transaction data proposed to date, by "de-identifying" transactions in ways consistent with Health Insurance Portability and Accountability Act guidelines. ${ }^{52}$

A thorough analysis of the tension between privacy and digital reference is a much longer discussion than is possible here; fortunately others have written such analyses. ${ }^{53}$ One issue that these authors have not explored, however, is the degree to which de-identifying transactions may restrict a service's ability to refer the user's question to another service. When a referral is made, how much information about the user must the referred-to service receive in order to accurately answer the user's query? Almost certainly the answer to this question depends on the user's query, but it bears future research. The existence of the developing QATP, however, allows for investigation of this question. One of the simplest use cases outlined for QATP is that "A sends the question to $\mathrm{B}$, requesting an answer. $\mathrm{B}$ processes the question, determines the answer, and sends it to A who then supplies the answer to the user" (www.loc .gov/standards/netref/usecases-secondworking-draft.html). In this use case, service A need share no transaction data or identifying information about the user with service $B$; as far as service $B$ is concerned, service A is the user, while as far as the user is concerned, service
B is invisible. Indeed, this QATP use case is reminiscent of Gross's imposed query, though with the difference that the user may be unaware that her query has been referred. This again begs the question of whether it is appropriate for a digital reference service to be a black box to the user.

Users may not care about the source of the information they receive, but libraries and librarians certainly do. Dempsey states that all documents produced by libraries should indicate the library's "brand," such as by utilizing a unique graphic identity. ${ }^{54}$ Similarly, answers from digital reference services should indicate their source in some way, such as a header or signature block in e-mail. This is not suggested to encourage services to steal users from one another, but rather as a simple way for services to market and brand themselves, so that users will come to associate a specific digital reference service-or perhaps better still, digital reference services in general—with useful and high-quality information.

In a 2004 webcast on Institutional Repositories (www.arl.org/training/ webcast/ir), Daniel Greenstein, the University Librarian for the California Digital Library, commented that scholarly publishing is undergoing radical changes, and that universities must not be afraid to experiment with new forms of publication and must not be afraid to fail in those experiments-that failed experiments are a useful method for learning and shaping the future. The same is true of collaboration in digital reference: reference services must not be afraid to experiment with new forms of collaboration and must not be afraid to fail in these experiments.

A discussion was started on May 25, 2004, on the Dig_Ref discussion list on the topic of chat reference services that have been shut down, and the reasons that these services have been discontinued (www.vrd.org/Dig_Ref/dig_ref shtml, Subject: "Shutting down chat reference"). Many postings have discussed libraries that have shut down their chat reference services, for reasons from lack of use to budget cuts. These reasons are echoed by Coffman 
and Arret, who also discuss the rapid rise and fall of commercial reference services during the 1990s. ${ }^{55}$ There may be solutions to the problems that have befallen these services; indeed, Coffman and Arret themselves suggest several methods for improving the operation of chat reference services. It may, however, ultimately be that chat reference service will prove not to be a viable method for offering reference service (though this author does not believe that). Indeed, Coffman hopes that chat will prove to be "an interim technology which will soon give way to something much more humane like voice. ${ }^{156}$ While at present it seems unlikely that Voice Over Internet Protocol (VoIP) will be adopted as a medium for reference work, Coffman raises legitimate concerns about chat being a somewhat cumbersome means of carrying on a conversation, and consequently of conducting a reference transaction. E-mail is in some ways even more cumbersome for this purpose. E-mail and chat may, as Coffman suggests, prove to be interim technologies for conducting reference work. VoIP may never be adopted as a medium for reference work, nor may blogs. If not, however, that would be a shame. These technologies are promising and worth experimenting with as media for reference work.

E-mail and chat have their problems, but these problems make us aware of issues in reference work that may not have previously been obvious, and teach us about reference work in general. Blogs, VoIP, and whatever will be the next technology to come along will also have their problems as media for reference work, but these problems will make us aware of yet more issues in reference work. All of these experiments with various media for reference work are learning experiences, not only for the library performing the experiment, but also for the profession as a whole. And, in the end, it is unlikely that any one technology will emerge as the medium for conducting reference work; it is far more likely that multiple technologies will continue to be used, each one good for reference work on particular topics or in particular environments or with particular users. It is only by experimenting with various technologies for reference work, and, perhaps, engaging in some failed experiments, that the profession of librarianship can learn which media are suitable for our own, and our users' purposes.

\section{CONCLUSION}

As technology progresses and users are increasingly able to find information for themselves online, it is increasingly important that digital reference services be able to provide answers to their users, or suffer the consequence that unsatisfied users may defect. In order for digital reference services to be able to provide answers to their users, it is ever-more important that services collaborate, sharing knowledge as any other resource might be shared.

As technology progresses, too, there inevitably will be new applications that may be useful for reference work and for collaboration between reference services, and these applications deserve a trial. The applications that exist and are used for collaboration between reference services today-print, telephone, e-mail, chat, discussion lists—all have their pros and cons. Future technologies for collaborative reference-blogs, VoIP, whatever the future brings—will have their own pros and cons. Reference services must, however, continue to experiment with new technologies for collaboration. It is only through such experimentation that the profession of librarianship will learn what applications are appropriate for what tasks and what reference environments. As services experiment with new technologies, successful experiments will lead to certain technologies being adopted by other services. Over time, as successful experiments become established practices, standards will be developed for these practices, and the existence of these standards will make the use of these technologies attractive to more services. In this way, as with e-mail and chat-based services, consortia will form that will enable services to share knowledge in new ways. The progress of technology has allowed, and will continue to allow, reference services to be- come more collaborative, to the benefit of both individual services and reference work in general.

\section{References and Notes}

1. Samuel S. Green, "Personal Relations between Librarians and Readers," American Library Journal 1 (Nov. 1876): 74-81.

2. Robert S. Taylor, "Question-Negotiation and Information Seeking in Libraries," College \& Research Libraries 29 (May 1968): 178-94.

3. Richard E. Bopp and Linda C. Smith, Reference and Information Services: An Introduction (Englewood, Colo.: Libraries Unlimited, 2001); William A. Katz, Introduction to Reference Work: Reference Services and Reference Processes, vol. 2, (New York: McGraw-Hill, 1997).

4. Herbert H. Clark and Deanna WilkesGibbs, "Referring as a Collaborative Process," Cognition 22 (1986): 1-39; Herbert H. Clark and Edward F. Schaefer, "Collaborating on Contributions to Conversations," Language and Cognitive Processes 2 (1987): 19-41; Gillian L. Roberts and Janet Beavin Bavelas, "The Communicative Dictionary: A Collaborative Theory of Meaning," in Beyond the Symbol Model: Reflections on the Representational Nature of Language, ed. John Stewart (State Univ. of New York Pr., 1996), 135-60.

5. David A. Tyckoson, "What Is the Best Model of Reference Service?" Library Trends 50 (Fall 2001): 183-96.

6. Clark and Wilkes-Gibbs, "Referring as a Collaborative Process," 3.

7. Clark and Schaefer, "Collaborating on Contributions to Conversations," 20.

8. N. J. Belkin, R. N. Oddy, and H. M. Brooks, "Ask for Information Retrieval: Part I. Background and Theory," Journal of Documentation 38 (June 1982): 61-71.

9. Mary Jo Lynch, "Reference Interviews in Public Libraries," The Library Quarterly 48 (Apr. 1978): 119-42.

10. Melissa Gross, "The Imposed Query: Implications for Library Service Evaluation," Reference \& User Services Quarterly 37 (Spring 1998): 290-99.

11. Thomas Childers, "The Test of Reference," Library Journal 105 (Apr. 1980): 924-28.

12. George S. Hawley, The Referral Process in Libraries: A Characterization of Related Factors (Metuchen, N.J.: Scarecrow, 1987).

13. Tyckoson, "What Is the Best Model of Reference Service?"

14. Emily Garnett, "Reference Service By Telephone," The Library Journal 61 (Dec. 1936): 909-11; Rochelle Yates, A Librarian's Guide to Telephone Reference Service 


\section{FEATURE}

(Hamden, Conn.: Shoe String, 1986); Rosemarie Reichel, "The Telephone Patron and the Reference Interview: The Public Library Experience," The Reference Librarian 16 (Winter 1986): 81-88.

15. Timestamp 1:21:35.

16. Barbara Berliner, Melinda Corey, and George Ochoa, Book of Answers: The New York Public Library Telephone Reference Service's Most Unusual and Entertaining Questions (New York: Simon \& Schuster, 1992); David Feldman, Imponderables (Quill, 1987); David Feldman, When Do Fish Sleep? And Other Imponderables of Everyday Life (New York: Harper, 1990); David Feldman, Do Penguins Have Knees? (New York: Harper, 1992 and several others by Feldman).

17. Charles R. Anderson, Puzzles and Essays from "The Exchange": Tricky Reference Questions (New York: Haworth, 2003), 165.

18. Renée Olson, "Stumped Reference Librarians Find Help on the Internet," American Libraries 25 (Oct. 1994): 830-31; Ann Feeney, "Internet Applications: StumpersL," Computers in Libraries 13 (May 1993): 40-42.

19. Feeney, "Internet Applications: Stumpers$\mathrm{L}, " 41$.

20. Nicholas C. Burbules, "Paradoxes of the Web: The Ethical Dimensions of Credibility," Library Trends 49, no. 3 (2001): 441-53.

21. Paul W. Kittle, "Putting the Medical Library Online: Electronic Bulletin Boards ... and Beyond," Online 9 (May 1985): 25-30; Ellen H. Howard and Terry Ann Jankowski, "Reference Services Via Electronic Mail," Bulletin of the Medical Library Association 74 (Jan. 1986): 41-44; Frieda O. Weise and Marilyn Borgendale, "EARS: Electronic Access to Reference Service," Bulletin of the Medical Library Association 74 (Oct. 1986): 300 304; Christine M. Roysdon and Laura Lee Elliott, "Electronic Integration of Library Services through a Campuswide Network," RQ 28 (Fall 1988): 82-93.

22. Laura Bushallow-Wilber, Gemma DeVinney, and Fritz Whitcomb, "Electronic Mail Reference Service: A Study," RQ 35 (Spring 1996): 359-69; Brenda Philip, "Mayihelpyou@Theelectronicreference desk?: An Examination of the Past, Present, and Future of Electronic Mail Reference Service," Mar. 20, 1997, http:// hollyhock.slis.ualberta.ca/598/brenda/ emailref.htm (accessed Apr. 27, 2005).

23. R. David Lankes, Building and Maintaining Internet Information Services: K-12 Digital Reference Services (Syracuse, N.Y.: ERIC Clearinghouse on Information $\&$ Technology, 1998).

24. Jeffrey Pomerantz, Scott Nicholson, and R. David Lankes, "Digital Reference Triage: Factors Influencing Question
Routing and Assignment," The Library Quarterly 73 (Apr. 2003): 104.

25. Blythe Bennett, e-mail to the author, July. 2004.

26. Nicholas Savard, Nigel Long, and Jeff Penka, "Professional Reference Anywhere, Anytime, Virtually: Helping Redefine the Role of Librarians and Libraries in the Internet Age" (paper, Alberta Library Conference 2004, Jasper, Alberta, Canada, 2004)

27. Jana Smith Ronan, Chat Reference: A Guide to Live Virtual Reference Services (Englewood, Colo.: Libraries Unlimited, 2003).

28. Jeffrey Pomerantz and Charles McClure, "Evaluation of a Statewide Collaborative Chat-Based Reference Service: Approaches and Directions," in Proceedings of the 67th Annual Meeting of the American Society for Information Science and Technology, ed. Linda Schamber and Carol L. Barry (Medford, N.J.: Information Today, 2004), 102-09.

29. For an overview of the sorts of library consortia that exist, Bernie Sloan maintains an extensive collection of links to online documents "dealing with the governance and administration of library consortia and cooperatives": www.lis uiuc.edu/ b-sloan/consort.htm (accessed July 10, 2006)

30. Jeffrey T. Penka, "The Technological Challenges of Digital Reference: An Overview," D-Lib Magazine 9 (Feb. 2003), www.dlib .org/dlib/february03/penka/02 penka .html (accessed Apr. 27, 2005); Savard, Long, and Penka, "Professional Reference Anywhere, Anytime."

31. David P. Reed, "That Sneaky Exponential-Beyond Metcalfe's Law to the Power of Community Building," Context Magazine (Spring 1999), www.contextmag.com/archives/199903/ DigitalStrategyReedsLaw.asp (accessed Apr. 27, 2005)

32. Kenneth Lavender, Scott Nicholson, and Jeffrey Pomerantz, "Building Bridges for Collaborative Digital Reference between Libraries and Museums through an Examination of Reference in Special Collections," Journal of Academic Librarianship 31, no. 2 (2005): 106-18.

33. Ibid., 116-17.

34. R. David Lankes, Question Interchange Profile, Online Version 1.01d, May 1999. Syracuse, N.Y.: ERIC Clearinghouse on Information \& Technology, www.vrd.org/ Tech/QuIP/1.01/1.01d.htm (accessed Apr. 27, 2005)

35. Nancy Kalikow Maxwell, "Establishing and Maintaining Live Online Reference Service," Library Technology Reports 38 (July/Aug. 2002): 1-78.

36. Cory Doctorow et al., Essential Blogging (Sebastopol, Calif.: O'Reilly and Associates, 2002)
37. Doug Goans and Teri Vogel, "Building a Home for Library News with a Blog," Computers in Libraries Magazine 23 (Nov./Dec. 2003): 21-26, www .infotoday.com/cilmag/nov03/goans _vogel.shtml (accessed Apr. 27, 2005); Darlene Fichter, "Why and How to Use Blogs to Promote Your Library's Services," Marketing Library Services 17 (Nov./Dec. 2003): 1-4, www.infotoday.com/mls/ nov03/fichter.shtml (accessed Apr. 27, 2005).

38. Blake Carver, "Is It Time to Get Blogging?" Library Journal netConnect (winter 2003), www.libraryjournal.com/ article/CA266428 (accessed Apr. 27, 2005). See, for example: Gary Price's ResourceShelf, www.resourceshelf. com (accessed July 10, 2006); Jessamyn West's librarian.net, www.librarian.net (accessed July 10, 2006); Jenny Levine's The Shifted Librarian, www theshiftedlibrarian.com (accessed July 10, 2006), and others

39. Burbules, "Paradoxes of the Web."

40. Lavender, Nicholson, and Pomerantz, "Building Bridges for Collaborative Digital Reference between Libraries and Museums," 106.

41. Chris Sherman, "ComScore Launches Search Engine Tracking System," Apr. 19 2003, searchenginewatch.com/searchday/ article.php/2197801/ (accessed Apr. 27, 2005); Joseph Janes, "The Global Census of Digital Reference" (paper, 5th Annual VRD Conference, San Antonio, Texas, Nov. 18, 2003). Janes's figure of 8,106 questions submitted to digital reference services worldwide is probably low due to the fact that his sample was one of convenience. A convenience sample is, however, the best that anyone doing research on digital reference services can currently do, since the makeup of the population of digital reference services is unknown. The determination of the "demographics" of the population of digital reference is an area that demands future research.

42. Joan C. Durrance, "Reference Success: Does the 55 Percent Rule Tell the Whole Story?" Library Journal 114 (Apr. 1989): 31-36.

43. Mary Jane Swope and Jeffrey Katzer, "Why Don't They Ask Questions?" RQ 12 (winter 1972): 161-66.

44. Glenn DeSouza, "Designing a Customer Retention Plan," Journal of Business Strategy 13 (Mar./Apr. 1992): 24-28.

45. American Library Association Reference and User Services Association, Guidelines for Information Services, 2000, section 1.12, www.ala.org/ala/rusa/rusaprotools/ referenceguide/guidelinesinformation .htm (accessed Apr. 27, 2005).

46. Joseph Janes, "Question Negotiation in an Electronic Age," in The Digital Ref- 
erence Research Agenda, ed. R. David Lankes, Scott Nicholson and Abby Goodrum (Chicago: ACRL, 2003), 4860; Joseph Janes and Joanne Silverstein, "Question Negotiation and the Technological Environment," D-Lib Magazine 9 (Feb. 2003), www.dlib.org/dlib/ february03/janes/02janes.html (accessed Apr. 27, 2005).

47. Christina M. Hull, "An Analysis of Information Literacy Instruction in the Digital Reference Service of a Public Library System" (master's thesis, University of North Carolina at Chapel Hill, 2004).

48. Virtual Reference Desk Project, Facets of Quality for Digital Reference Services, Version 5, June 2003. www.vrd .org/facets-06-03.shtml (accessed Apr. 27, 2005).

49. Joseph Janes, "Digital Reference Services in Public and Academic Libraries," in Evaluating Networked Information Services: Techniques, Policy, and Issues, ed. Charles R. McClure and John Carlo Bertot (Medford, N.J.: Information Today, 2001), 184.

50. Paul Neuhaus, "Privacy and Confidentiality in Digital Reference," Reference \&
User Services Quarterly 43 (Fall 2003): 26-36; ALA, Code of Ethics of the American Library Association (Chicago: ALA, 2004), www.ala.org/ala/oif/statementspols/ codeofethics/codeethics.htm (accessed Apr. 27, 2005).

51. A. Clymer, "Librarians Get Advice on Handling Government Requests for Information on Readers," New York Times, Dec. 12, 2002, A30; D. E. Murphy, "Some Librarians Use Shredder to Show Opposition to New F.B.I. Powers," The New York Times, Apr. 7, 2003, Al2

52. Scott Nicholson and Catherine Arnott Smith, "Using Lessons from Health Care to Protect the Privacy of Library Users: Guidelines for the De-Identification of Library Data based on HIPAA" (paper, Annual Meeting of the American Society for Information Science and Technology 2005, Charlotte, North Carolina, 2005), available as an E-print via the following service (http://eprints/rclis.org/ archive/00005222/fullmetadata.html, accessed July 10, 2006).

53. Scott D. Johnston, "Rethinking Privacy for the Virtual Library," in Implementing Digital Reference Services: Setting Standards and Making It Real, ed. R. David Lankes et al. (New York: Neal-Schuman, 2003); Neuhaus, "Privacy and Confidentiality in Digital Reference."

54. Beth Dempsey, "Target your Brand," Library Journal 129 (Aug. 2004): 32-35.

55. Steve Coffman and Linda Arret, "To Chat or Not to Chat-Taking Another Look at Virtual Reference, Part 1," Searcher 12 (Jul./Aug. 2004): 38-49, www .infotoday.com/searcher/jul04/arret _coffman.shtml (accessed Apr. 27, 2005); Steve Coffman and Linda Arret, "To Chat or Not to Chat-Taking Yet Another Look at Virtual Reference, Part 2," Searcher 12 (Sept. 2004), www infotoday.com/searcher/sep04/arret _coffman.shtml (accessed Apr. 27, 2005)

56. Steve Coffman, "We'll Take It from Here: Developments We'd Like to See in Virtual Reference Software," Information Technology and Libraries 20 (Sept. 2001): 149-53, www.ala.org/Content/ $\mathrm{N}$ avigation M en u/LI T A/LI T A _Publications4/ITAL__Information _Technology_and_Libraries/2003 _Coffman.htm (accessed Apr. 27, 2005).

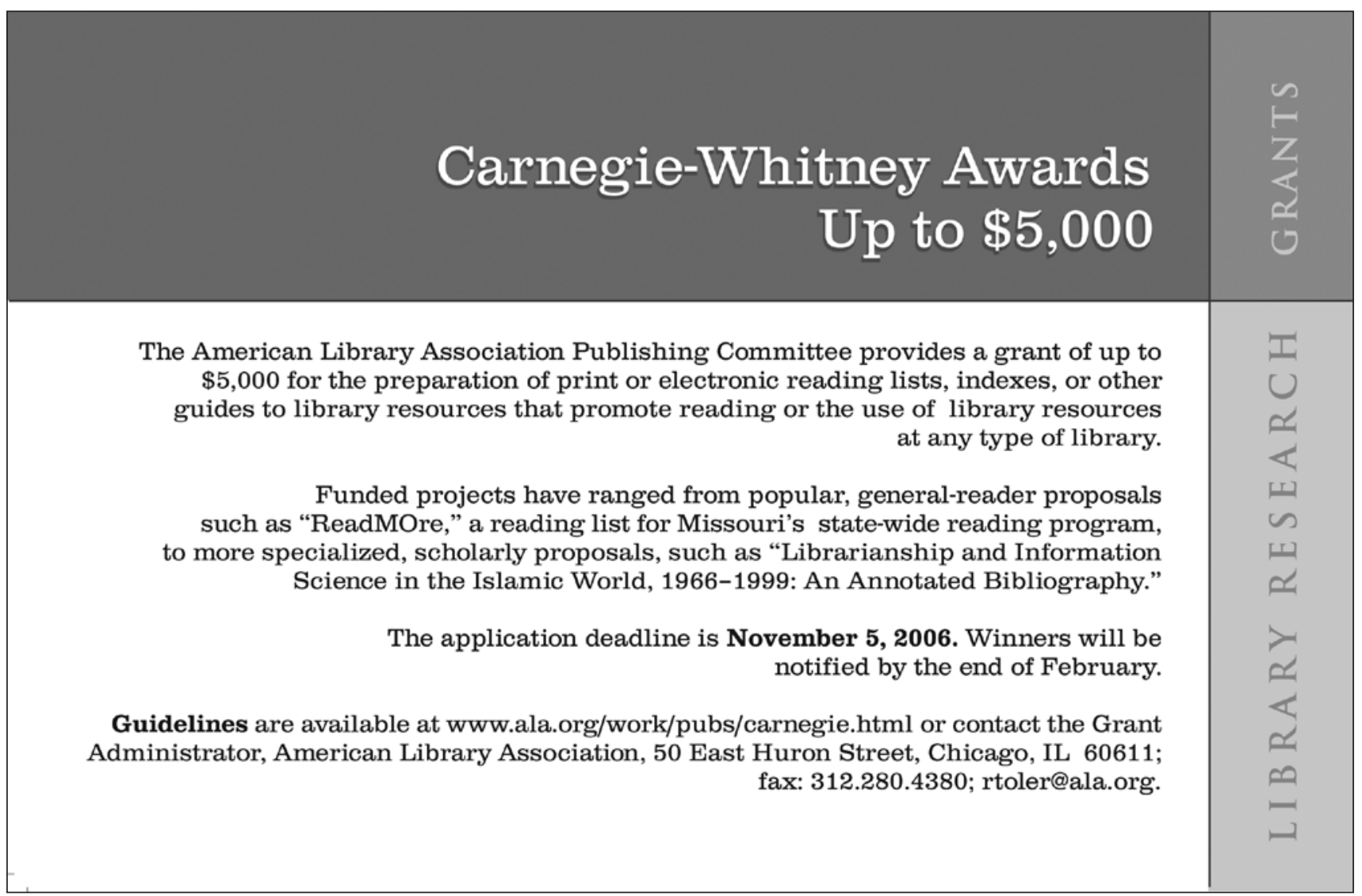

